\title{
Analysis of Biomechanical Behaviour of Anterior Teeth Using Two Different Methods: Finite Element Method and Experimental Tests
}

\author{
Laura M. Bessone1, Enrique Fernández Bodereau1, Gabriela Cabanillas', \\ Alejandro Dominguez ${ }^{2}$ \\ ${ }^{1}$ Department of Clinical Prosthodontics, Dental School, National University of Cordoba, Córdoba, Argentina \\ ${ }^{2}$ Materials and Technology Department, FCEFyN, National University of Cordoba, Córdoba, Argentina \\ Email: laurabessone@hotmail.com
}

Received 24 October 2013; revised 24 November 2013; accepted 4 December 2013

Copyright (C) 2014 by authors and Scientific Research Publishing Inc.

This work is licensed under the Creative Commons Attribution International License (CC BY).

http://creativecommons.org/licenses/by/4.0/

\section{Abstract}

The main objective of this study was to compare the results obtained with both virtual and experimental research methods, when the biomechanical behavior of teeth restored with esthetic posts was investigated. The finite element method was used to develop models of healthy maxillary canines and maxillary canines restored with definitive crowns and glass-fiber posts, quartzfiber posts, and titanium posts. Stress distribution was observed when external loads were applied. Load was applied in-vitro to analyse the fracture resistance of 48 maxillary canines restored in the same way as it was considered in the virtual method. The analysis of results using the finite element method led to the conclusion that restored teeth, in which the elastic modulus of the post was similar to that of the dentine and the material of the core had the best biomechanical performance. The experimental study validated the virtual analysis.

\section{Keywords}

Compressive Strength; Glass Fiber Posts; Quartz Fiber Posts; Finite Element Method

\section{Introduction}

Posts are structures bound to the radicular portion connection and to the crown restoration of the endodontically treated teeth, which also take part in distributing strengths to the supporting or contact areas with the alveolar 
bone [1]. In early 1960, literature presented metal free posts, also called third generation, but they started being clinically used in 1990, as it is the case of fiber posts [2].

These fiber posts are characterized for having a low elastic modulus, like the dentine one, which allows them to absorb and dissipate the loads that are transferred to the dentine without radicular fractures. Therefore, most of recent studies have shown that compressive strength of these posts results in higher fracture strength of the restored teeth, unlike what happens with metal posts [3].

The Finite Elements Method (FEM) has been applied in this study so as to compare the behavior of natural healthy teeth with restored teeth under different loads. The experimental stage of this investigation was done on samples by applying compression loads with an Instron machine prepared for this purpose.

The upper canines were the teeth chosen since, in our opinion, are the most representatives of the anterior and superior parts of the oral cavity due to their important functional activity.

Three prefabricated posts systems were used for this job: titanium posts, glass fiber posts and quartz fiber posts. The control group was constituted by healthy upper canines, all of them restored with permanent metal crowns.

The main goal of this study was to compare FEM results with experimental results to prove whether virtual analysis is suitable for the teeth biomechanical behavior with different variables. The more specific aims were 1) analyzing stress distribution in teeth restored with esthetic posts; 2) performing an experimental study of fracture resistance and type of fracture in teeth restored with identical esthetic posts.

\section{Materials and Methods}

\subsection{Finite Element Method}

Creating the models of healthy maxillary finite canines and diverse restoring treatments was the main procedure developed to implement this study. The use of a titanium post (Komet, EEUU), a glass fiber post (Glassix, Nordin) and a quartz fiber post (Aesthetiplus, Bisco, EEUU), all of them with resin core build ups (Enforce core, Dentsply) and metal crowns (Figure 1) was included in the varied treatments.

The 3 stages of the above mentioned procedure are described in detail hereinafter:

A. Preliminary design: the geometry of the finite element models was created using CATIA, a CAD program. Through the importation of CATIA geometry to Abaqus/CAE, version 6.4 (USA, 2003, four finite element models and three submodels were done; whith four nodes tetrahedrons and eigth nodes hexahedrons (Table 1).

B. Definition: in this stage, material characteristics (density, elastic modulus) (Tables 2 and 3), and mastication process (loads to apply) were defined.

For the application of the virtual compressive loads over the upper canine, a $3 \mathrm{~mm}$ cylinder was used, $45^{\circ}$ with regards to its longitudinal axis at the cingulum level (mid-third of the palatal); that is, obliquely to its longitudinal axis to simulate the situation of the oral cavity receiving the loads. A progressive load was applied to all models of finite elements (healthy and restored) until determining the beginning of dentine fracture in some

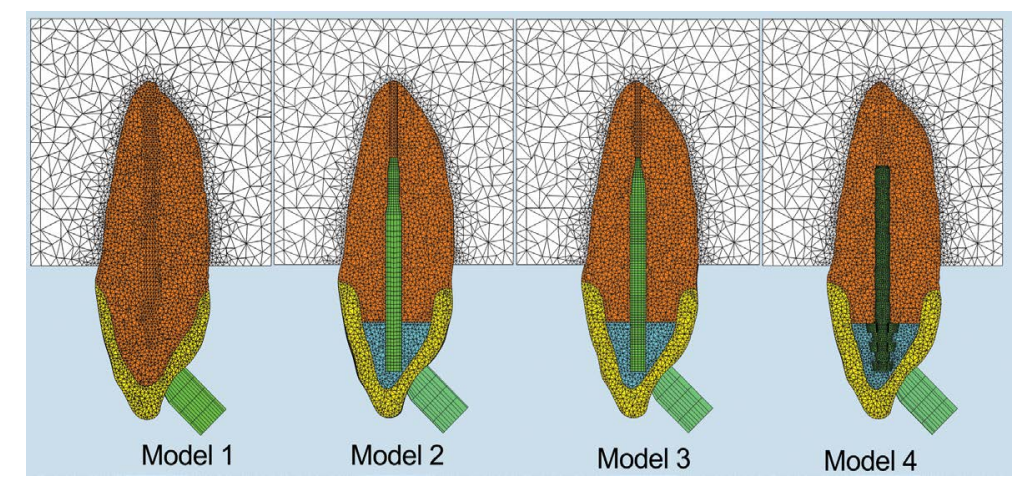

Figure 1. Finite element models. Note the reproduction of all its components including the alveolar bone. Model 1: natural teeth (maxillary canine). Model 2: finite element model of teeth restored with quartz fiber post. Model 3: a finite element model of teeth restored with glass fiber post. Model 4: finite element model of teeth restored with titanium posts; all of them have metal crowns. 
Table 1. Finite element models.

\begin{tabular}{cccc}
\hline Models & Description & Elements & Nodes \\
\hline 1 & Natural teeth & 288,777 & 60,871 \\
2 & Quartz fiber post. Metallic crown & 281,971 & 62,032 \\
3 & Glass fiber post. Metallic crown & 281,938 & 62,952 \\
4 & Titanium post. Metallic crown & 324,957 & 70,103 \\
\hline
\end{tabular}

Table 2. Mechanic's properties of materials.

\begin{tabular}{ccc}
\hline & Young's modulus E (MPa) & Poisson's coefficient \\
\hline Dentine & 18,000 & 0.31 \\
Alveolar bone & 1370 & 0.30 \\
Metallic crown & 200,000 & 0.33 \\
Titanium posts & 103,400 & 0.33 \\
Resin & 18,530 & 0.28 \\
Enamel & 41,000 & 0.30 \\
Cement & 2700 & 0.30 \\
\hline
\end{tabular}

Table 3. Longitudinal andtransversal young’s modulus. Poisson's coefficient of fiber posts.

\begin{tabular}{ccc}
\hline GLASS FIBER POSTS AND QUATRZ FIBER POSTS & \multicolumn{2}{c}{ Material } \\
\cline { 2 - 3 } E11: longitudinal Young's modulus(MPa) & Glass fiber/Epoxi resin & Quatrz fiber/Epoxi resin \\
E22: longitudinal Young's modulus(MPa) & 40,000 & 48,200 \\
E33: longitudinal Young's modulus(MPa) & 11,000 & 8200 \\
G12: transversal Youn's modulus(MPa) & 11,000 & 3000 \\
G13: transversal Young's modulus (MPa) & 4200 & 3000 \\
G23: transversal Young's modulus(MPa) & 4200 & 1300 \\
n12: Poisson's coefficient & 4100 & 0.32 \\
n23: Poisson's coefficient & 0.26 & 0.32 \\
n13: Poisson's coefficient & 0.26 & 0.32 \\
\hline
\end{tabular}

place of the model.

C. Analysis of Results: the common studied parameters are the tensional state and the model deformations. This study was done considering the Von Mises stress criterion. Moreover pure traction stress (S33 in the results) was considered since these stresses will probably initiate the cracks. Besides, the Von Mises stress shows the stress distribution, where nature of such stress cannot be determined (traction or compression). That is, it is a criterion indicative of the level of stress average, where the highest value indicates possibility of fracture [4].

\subsection{Work Materials}

Fiber posts: the posts used in this study are made up of a resin matrix containing different reinforcing fibers. A $36 \%$ of the matrix is composed by epoxy resin or some derivatives, which binds through free radicals common to the BisGMA resin adhesive cement. The increase of the mechanical characteristics is directly proportional to 
the entered fibers and to the binding of interface with the matrix.

Regarding quartz fiber posts, they are made up of quartz fibers (62.5\%) that give them excellent mechanical characteristics. Fibers are arranged in one direction, in an epoxy resin matrix, with an elastic modulus similar to that of the dentin (18.6 GPa). This would mean a better strength distribution along the post and an advantage for the dental structure.

The backup glass fiber technology based on fibers oriented in one direction or in mesh type, and embedded in BisGMA organic matrices were also used in this study. Fibers have a $61.5 \%$ of weight in glass fiber; this percentage may vary according to the brand. The elastic modulus is between 20 and $22 \mathrm{GPa}$ average, similar to that of the dentine [5].

Titanium posts: are made up of titanium, or steel and titanium alloys. They have a smooth surface, spiral or retentive thread for the cement, but in no case there is contact between the bolt and radicular surface. They do not have active retention inside the root canal, such as the threaded posts, and can be used with any kind of cement [6].

Material for core build-up reconstruction: composite resins [7] were the chosen materials [8] for the reconstruction of the remaining crowns. The modern composites have stuffing that increase resistance and elasticity of the modulus, reduce polymerization contraction, thermal expansion coefficient and water absorption.

Cements: the selected cement for the prefabricated posts was the composed resin cement. The cementing of the posts with based BisGMA cement allows obtaining a homogeneous structure that stands between the post and the residual dental tissue. The elastic modulus of the BisGMA loaded resin is $20 \mathrm{GPa}$, which turns this resin into the ideal binding between the post and the dental tissue. The thickness of the resin connects the post to the tissue of the prepared root canal and mechanically replaces the dentin [4].

\subsection{Experimental Test of Fracture Resistance}

Once FEM was finished, followed the experimental testing for evaluating the fracture resistance level. Therefore, 48 maxillary canines removed for periodontal reasons from men, between 35 and 50 years old, were selected [9] [10].

They were kept in saline solution during the preparation and once they were ready for use, the roots shorter than $12 \mathrm{~mm}$ were discarded and grouped according to similar oral cavities width. The control group was made up of 12 samples without endodontic treatments and prepared only for receiving metal crowns. 48 maxillary canines were worn out up to $3 \mathrm{~mm}$ before the cementoenamel junction. Much cooling was used thus creating a protection area (splint effect) around the preparation in order to withdraw the gutta-percha and prepare the root canals with the material provided by the manufacturer of each used post.

In depth, all posts measured up to $10 \mathrm{~mm}$ long $( \pm 1 \mathrm{~mm})$ having a minimum $4 \mathrm{~mm}$ of apical obturation. The root canals were etched with 32\% phosphoric acid (Unitech, Bisco, USA) for 15 seconds, then a profuse water spray wash for 30 seconds was done and finally the wiping.

Then a fifth generation adhesive One Step Plus (Bisco, USA) was applied on the wall of the root canal, it is a universal adhesive with filling. The root canal was airily dried for 5 seconds and then halogen light exposition during 20 seconds.

After silanization of the fiber posts, they were coated with the same adhesive. The self-curing resin cement was introduced with lentulo for a better distribution in the canal root walls. Core build up was done with curing resin. All samples were carved with diamond saw and the vestibular and proximal grooves of $15 \mathrm{~mm}$ of thickness, the palatal groove of $1.2 \mathrm{~mm}$ and the incisal groove $2 \mathrm{~mm}$ were marked. These measures as well as the posts $(7 \mathrm{~mm})$ were standardized so as to have all crown restorations with the same dimensions. A bisel shoulder in all posts was done to achieve a marginal adjustment of the metal (Figure 2). The control group was made up of 12 natural healthy teeth carved with crowns. Then, the casting crowns in non purity chromo and nickel metal alloys were made (Vera Soft, Aalba Dent-Cordelia, California, USA).

Crown restorations were directly done on the samples of the prepared posts for each group. Before this, a layer of VITA interspace varnish (for pure porcelain crowns) was applied since it warranted a space of 25 to 50 um, which would later be destined for cementing (Table 4).

All samples were included in a photopolymerizing acrylic block up to the same height where the Teflon tape is applied, i.e. $2 \mathrm{~mm}$ under the cementoenamel junction, to mimic the natural biologic thickness. They were taken to a device, made up of a steel cylinder with a tube having a $45^{\circ}$ tilting, which held the samples for the 


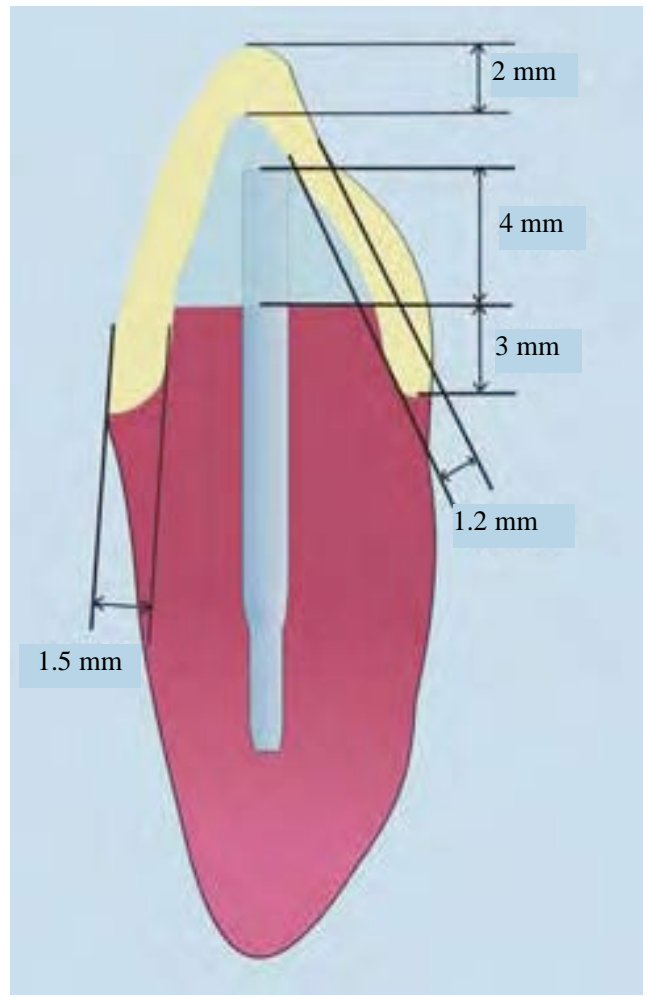

Figure 2. Submodel of crown margin.

Table 4. Samples.

\begin{tabular}{cccccc}
\hline Group & Samples & Posts & Cement & Core material & Type of crown \\
\hline I & 12 & Titanium passives (Komet, USA) & C\&B & Enforce core & Metallic \\
II & 12 & Quartz fiber Aesthetiplus (Bisco, USA) & (Bisco, USA) & (Dentsply, USA) & Metallic \\
III & 12 & Glass fiber posts(Glassix, Nordin) & C\&B & Enforce core & Metallic \\
IV & 12 & Natural teeth & (Bisco, USA) & & Metallic \\
\hline
\end{tabular}

compressive load test. At this preparation level, samples were placed in an INSTROM 4486 machine to apply the loads, in vitro, in a $45^{\circ}$ direction regarding the dental element edge [11] [12] (Figure 3).

Loads were applied to group I, II, III and IV (control) samples until some of the system components broke down and thus the load values responsible for the fractures could be compared.

\section{Results}

\subsection{Finite Elements Method}

In Figure 4, S33 stress distribution is shown (tension component in the longitudinal axis of the tooth). Once the load was applied it was observed a stress concentration in the fiber posts systems at level of the crown cervical edge almost in the alveolar junction. This was because the material of the core build up (composed resin) has an elastic modulus relatively low compared to the surrounding materials (metal or porcelain of the crown). In the case of metal posts with similar stiffness to the crown materials, the cervical zone had less stress.

The compressive load applied, originated vestibular compression tensions and palatine traction at alveolar bone junction level. When load was applied, a vestibular compression was generated reaching outliers values to the resistance of the dentine compression (297 Mpa). This indicated that samples would not break down for the compression but for the traction generated by the palatine. This result was observed in all studied models. 


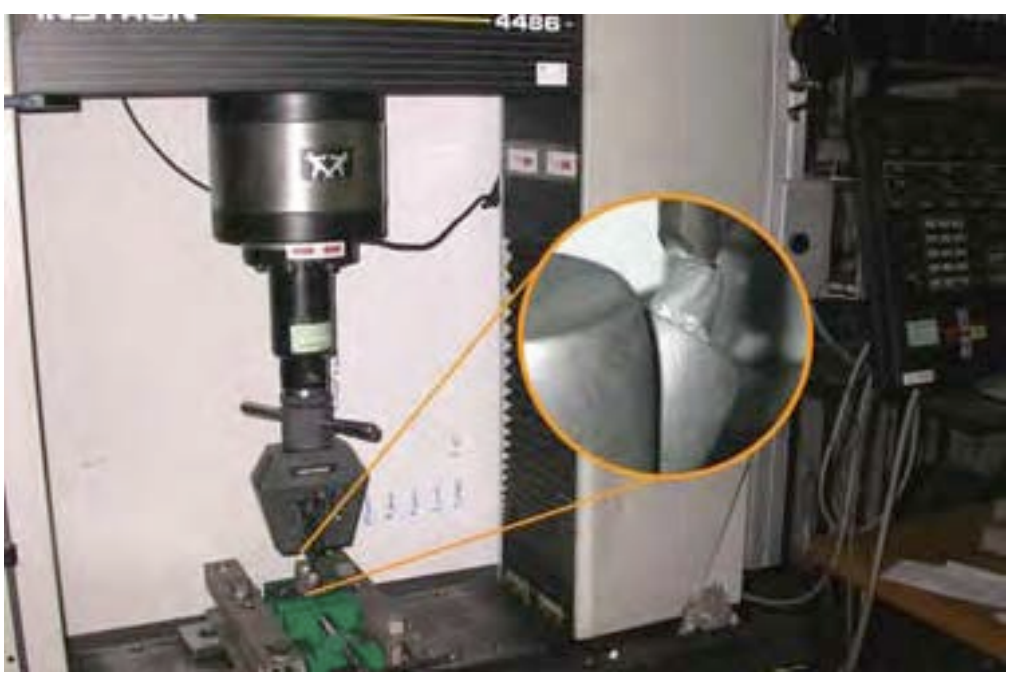

Figure 3. Reconstruction with standardized measurements.

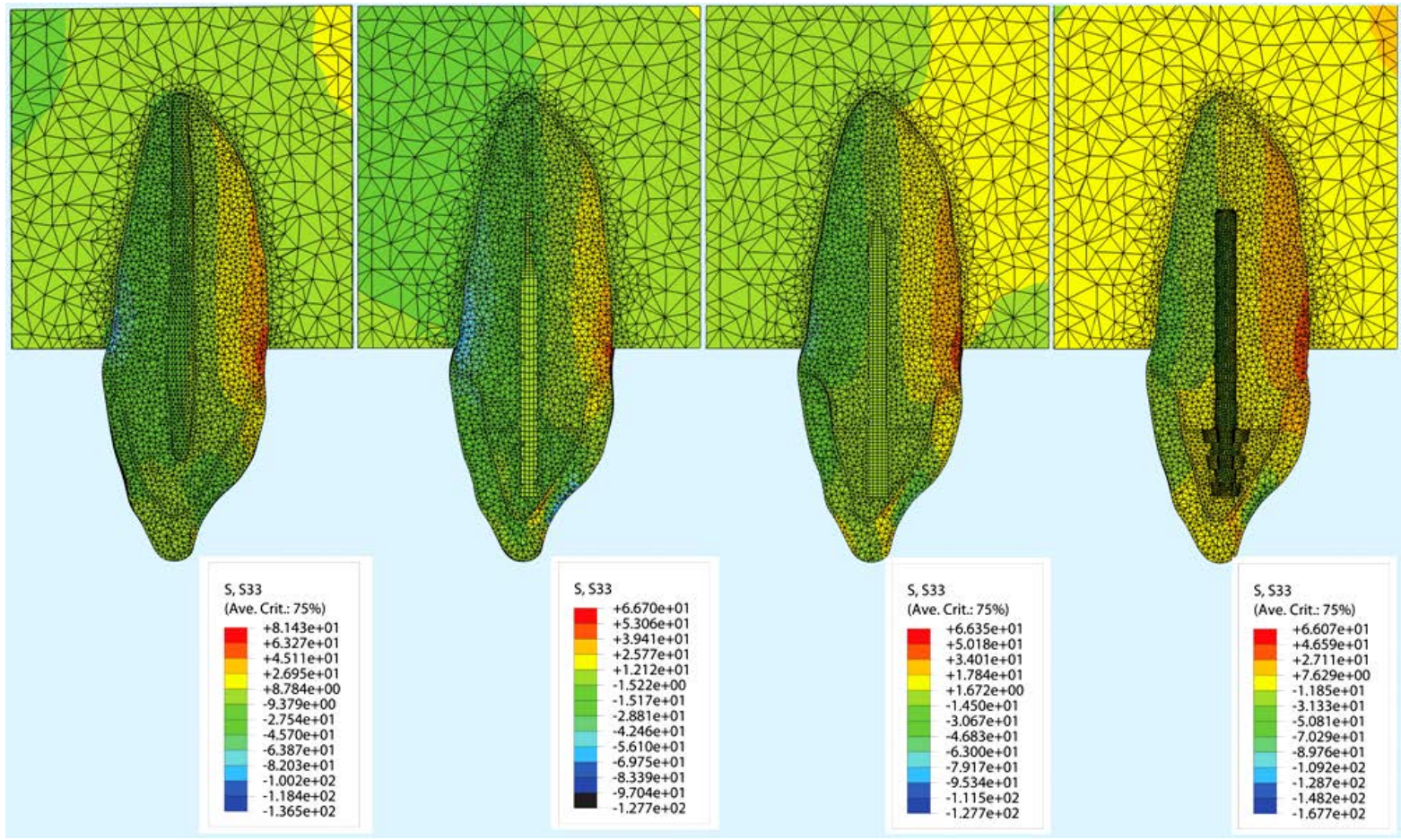

Figure 4. Instron 4486 machine. Sample subjected to compressive load.

Regarding stress concentrations generated within the posts under compression loads over $550 \mathrm{~N}$, a higher stress level was produced at the posts mid-third and apical junction and the teeth. The titanium post absorbed the highest stress, while the glass fiber post had the lowest stress concentration.

Figure 5 shows the values of Mises stress (indicative of possible fractures). Models 1 (natural tooth) and 3 (restored element with glass fiber post) under a load of $550 \mathrm{~N}$ showed similar stress values.

In Figure 6, the values of S33 stress in the finite element models were compared. S33 were produced in the palatine at the cervical level. In the natural tooth and in the glass fiber post model, stress were similar and lower than in the other two models, something likely occurred in model 2 (quartz fiber posts) and in model 4 (titanium post). The dentine tensile strength was $85 \mathrm{Mpa}$. Therefore, it was considered that restored teeth with quartz fiber and titanium broke down before natural teeth and restored teeth with glass fiber. 


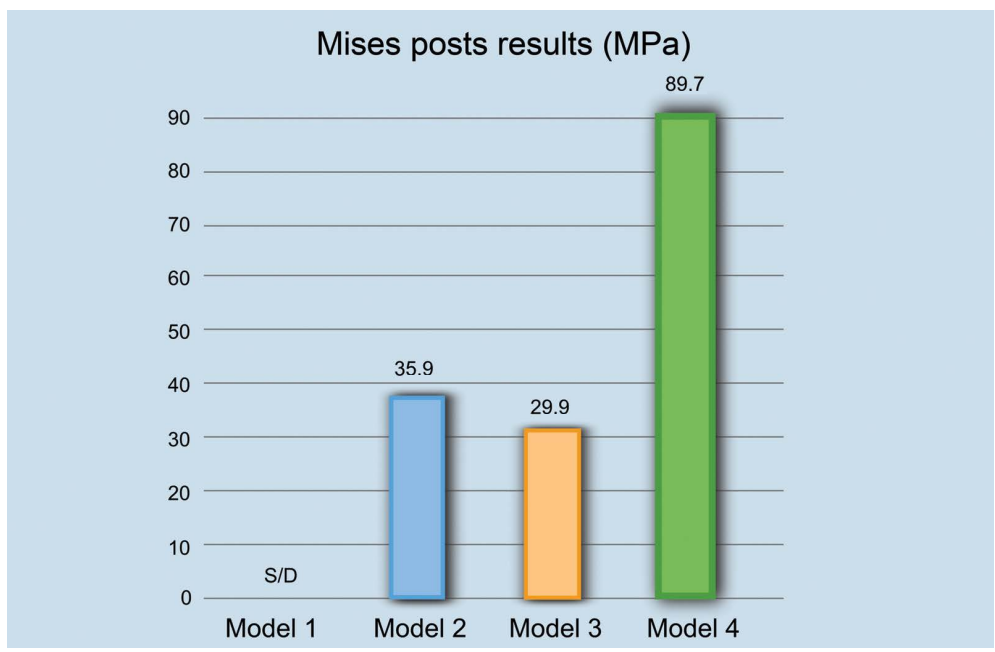

Figure 5. The Von Mises stresses, potential fracture indicators, under a load of $550 \mathrm{~N}$ show similar values for model 1 and model 3.

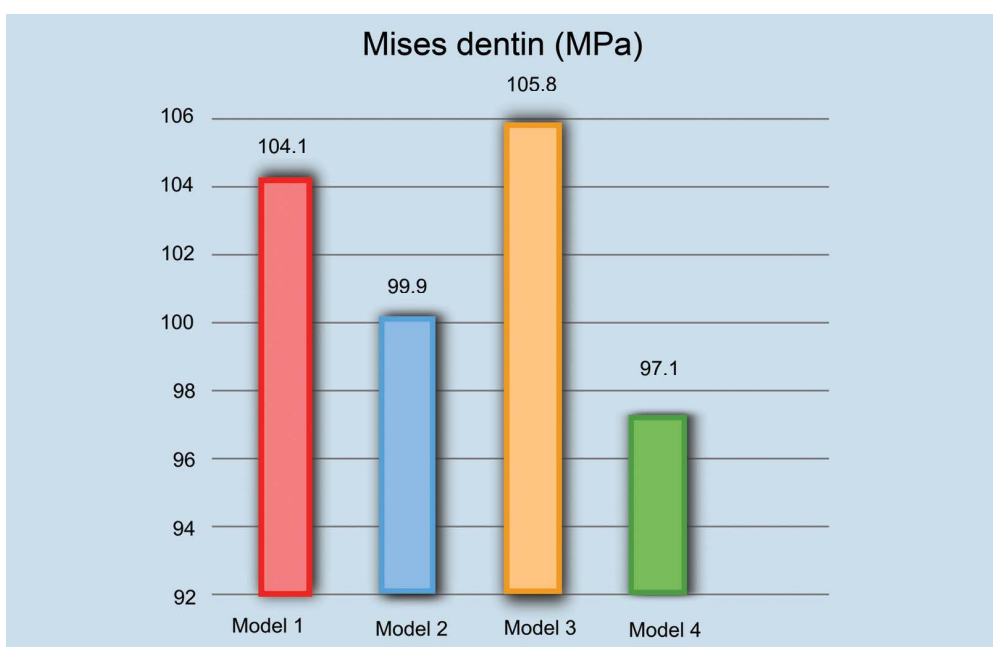

Figure 6. FEM shows that a load of $493.3 \mathrm{~N}$ is needed to overcome the adhesive resistance of the cement joining the crown to the tooth in the models with quartz fiber posts; a load of $439.2 \mathrm{~N}$ in glass fiber posts, and a load of $422.8 \mathrm{~N}$ in titanium posts, without causing visible changes.

\subsection{Experimental Test}

\section{Compresive Strength}

A non parametrical statistics analysis through the Mann-Whitney $U$ test to compare the independent variables of two groups was done. In case of three or more independent variables, the Kruskal-Wallis test was used. All data was considered statistically significant if p was lower or equal to 0.05 .

Through statistical analysis, it was able to prove that results were statistically significant $(\mathrm{p}<0.05)$ when prefabricated samples with quartz fiber posts are compared to healthy teeth (control group).

Natural teeth group (control) was the most resistant to compression. The glass fiber posts group had similar values to those registered in the natural teeth group (Figures 7 and 8).

\section{Discussion}

\subsection{Finite Elements Method}

Finite elements method allows knowing the stress distribution in complex structures. The effectiveness depends 


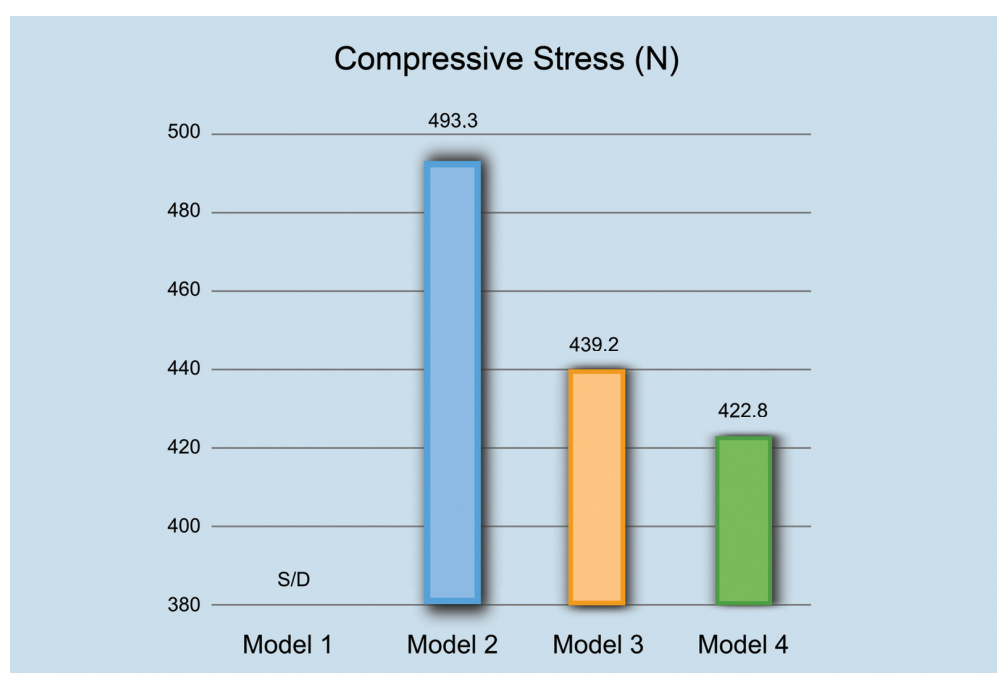

Figure 7. Natural teeth group (control) was the most resistant to compression. The glass fiber posts group had similar values to those registered in the natural teeth group.

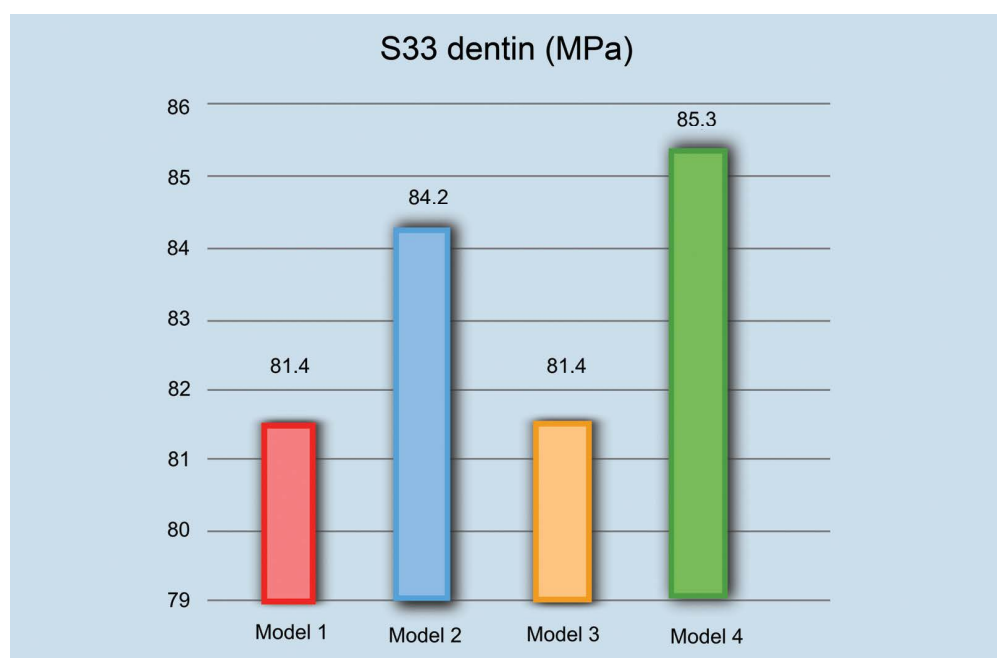

Figure 8. Stresses S33 are traction stresses that occur in the palatal cervical area. They are similar in the natural tooth and in the glass fiber post, but lower in the other two models. Resistance to traction of the dentine is $85 \mathrm{Mpa}$, and is very close in models 2 and 4.

on the study closeness to the real clinical model.

Diverse authors have demonstrated by in vitro experiments the effectiveness of the finite elements analysis as a method of work to foresee an approximate of the clinical biomechanical behavior of the teeth restored with posts [9] [10] [13]-[15].

In this investigation, the fiber post systems produced a stress concentration on the cervical edge of the crown, almost at the alveolar bone junction, which might occur because the core build up material has a Young modulus relatively low in comparison to the surrounding materials (metal crown). On the contrary, the metal posts have a similar rigidity to the ones of the crown materials; thus, the cervical area should have less stress as it was observed by Toksavul et al. in a previous investigation [4].

Other investigators have shown that the bigger the difference between the teeth Young modulus and posts, the less homogeneous the stress distribution on the teeth surface, and this causes areas of stress concentration in the dentin.

Kol et al. showed in a study that posts changed tensions on the teeth under vertical loads of compression [16]. 
Since in our investigation these results could be confirmed, we can say that posts affect the distribution of the loads on the dentin.

In a similar study, Ekstascioglu et al. observed that tensions accumulated inside the metal posts, and this was an advantage for dental structures and the supporting tissues, but at the same time it was a disadvantage for the third apical of the restored tooth [9]. When fiber posts were evaluated, it was observed that the stress accumulated in the cervical region and along the vestibular bone although there was less stress concentration in the post structure.

Regarding tensions concentration generated inside the posts under a compression load of $550 \mathrm{~N}$, it was proved in this investigation that not only a bigger tension area existed in the third mid and apical junction of the post as the tooth causing break downs at this level, but also that titanium post absorbed the highest tension. At its time, it was seen the lowest tension concentration in the model with glass fiber posts, which could be translated in interface failures (per-no-cement-dentin), as it was shown in other investigations [11].

Eraslan et al. [17] studied and compared the stress distribution on the tooth by using the finite elements method. 3 D models were analyzed simulating endodontically treated maxillary central incisors with ceramic crowns. The tension values observed in the zirconium posts were higher, due to its rigidness, than in the glass fiber posts. That is, these latter studies agreed with our results.

The applied $550 \mathrm{~N}$ static compressive force created compression tensions by vestibular and palatine traction at the alveolar bone junction level. The compression that is generated by vestibular does not feat the resistance to samples fractures. Based on this, it was concluded that the traction generated by the palatine in all models with posts surpassed the resistance to traction of natural tooth and was responsible for the rupture of the tooth at that level.

Pegoretti et al. [18], in a study where FEM was used, observed that glass fiber posts showed less tensions in the root compared to metal and carbon fiber posts.

Lanza et al., compared, through the finite elements method, carbon, quartz and steel posts with a load of $10 \mathrm{~N}$ over 125 maxillary incisives. The steel post $(\mathrm{E}=200 \mathrm{Gpa})$ was the one that transmitted most load to the root; the quartz post, the least; and the carbon post was similar to quartz post [19].

Other authors that agree with our findings are Adanir et al., [20] who have recently evaluated in an investigation the effect of the different post materials in tensions distributions in endodontically treated maxillary central incisors using a 3D model of finite elements of modified incisors with five variants of posts with different physical properties, stainless steel, titanium, gold, glass fiber (Snowpost) and carbon fiber (Composipost). A $200 \mathrm{~N}$ load was applied in different directions; a) vertical, b) oblique at $45^{\circ}$ of the cingulum level. Tensions distribution was calculated according to Von Mises criterion. Their results were also similar to our results. Under different loads, the steel posts showed a higher tensions concentration in the post-dentin interface, followed by titanium, gold, Snowpost and Composipost. However, fiber posts showed great tensions concentration at the crown third cervical level. Their conclusions were that physical characteristics of the posts were important for the tensions distribution in the posts and core build ups. Glass fiber posts revealed more balanced tensions distribution under compressive loads application.

\subsection{Experimental Test}

\section{Compression Resistance}

Many authors have agreed that it does not exist in dentistry a restoring technique to be applied in all clinical cases; therefore, within the indications for restoring a devitalized tooth with posts, there is a percentage of cases to choose between metal post or fiber post [21]-[23].

In this investigation, the more resistant group to compression was the natural teeth restored with metal crowns group. Then, as it is shown in other similar studies, the control group had higher strength, which shows the importance of keeping the tooth remainder. Regarding compression resistance, the glass fiber posts group had similar values to the natural teeth group, and the titanium posts worked with little difference. On the other hand, the dental elements with quartz fiber posts had the lowest resistance values.

Newman et al. [24] also compared the anterior teeth with different ways of endodontically restored teeth with glass fiber posts, Fibrecor, Luscent Anchor, Ribbond Posts and stainless steel. They were under compression loads and the conclusion was that fracture resistance was higher with metal posts than the two studied fiber posts. However, the kid of fracture of the posts reinforced with fiber resulted less damaging for the remaining dental 
structure. There were not root fractures in any of the experimental groups with fiber cores. In the metal cores, 3 fractures were detected in 10 roots. It is important to point that these investigators did not apply crown to the samples; therefore, loads were applied directly on core build ups. Although for Hayashi et al. [25] fracture resistance of the metallic core build ups was also higher than the fiber posts, their conclusion was that the combination of fiber posts and resin core build up with metallic crowns were more favorable for the remaining dental structure.

Maccari et al., [26] in a comparative study between glass fiber posts, carbon fiber posts coated with quartz and ceramic posts, determined higher values of resistance and similar among them for the organic posts and lower for the ceramic posts.

Cormier et al. [27] compared fracture resistance and kind of failure of fiber posts, ceramic posts, cast posts and prefabricated metallic posts under different types of loads. In this study, posts underwent a load of $90^{\circ}$ after being cemented but without constructing the core build up, and after applying a crown on the same core. Fiber posts showed advantages over metal and ceramic posts, since the samples with the most rigid posts suffered unrecoverable break downs. In those cases where the roots were possibly recovered, a fiber post was applied. Besides, the breakings down limits were similar and only the Fibrekor were more resistant than the others.

Gordon et al. [28] said that due to the posts fiber-resin interface properties and their relative flexibility, not only a few cracks occur in the post structure but also a minimization of microcracks spread to the tooth roots. With regards to the resin cements that absorbed the loads sent by the dental structures, it might be said that also collaborated with this statement, since the use of cements allowed that restorations behaved as real structural units. The results imply that differences between the elasticity of post-core-dentin could be the origin of tensions concentration in the interface core-cement-post that break the restored tooth.

\section{Conclusions}

After analyzing the results and the comparison of the theoretical and experimental methods, we can conclude that both share the following items:

- The dentine rupture is caused by traction and begins in the palatine side of the samples, near the bone junction, where higher tensions are concentrated in the FEM.

- The teeth with metal posts and crowns suffer fractures or cracks after applying strengths over $550 \mathrm{~N}$.

Within the limits of this investigation, we concluded that, using an experimental method to obtain the virtual method validation, let us confirm that the finite element analysis allows foreseeing the biomechanical behavior of the teeth with diverse variables.

\section{References}

[1] Angobaldo, A.S. (1999) Factores Biomecánicos de Resistencia de la Dentina del Diente Endodónticamente Tratado. Revista Mundo Odontológico (Perú), 37, 40-44.

[2] Duret, B., Duret, F. and Reynaud, M. (1996) Long Life Physical Property Preservation and Postendodontic Rehabilitation with the Composipost. Compendium of Continuing Education in Dentistry Supplement, S50-S56.

[3] Ho, M.H., Lee, S.Y., Chen, H.H. and Lee, M.C. (1994) Three Dimensional Finite Element Analysis of the Effect of Posts on Stress Distribution in Dentin. The Journal of Prosthetic Dentistry, 72, 367-372. http://dx.doi.org/10.1016/0022-3913(94)90555-X

[4] Toksavul, S., Zor, M., Toman, M., Güngör, M.A., Nejgis, I. and Artunc, C. (2006) Analysis of Dentinal Stress Distribution of Maxillary Central Incisors Subjected to Various Posts and Core Applications. Operative Dentistry, 31, 89-96. http://dx.doi.org/10.2341/04-192

[5] Malferrari, S., Mónaco, C. and Scotti, R. (2003) Clinical Evaluation of Teeth Restored with Quartz-Fiber Reinforced Epoxy Resin Posts. The International Journal of Prosthodontics, 16, 39-44.

[6] Vega del Barrio, J.M. (1996) Sistemas Adhesivos. En: Materiales en Odontología, Ediciones Avances, Madrid, 315-332.

[7] De Jager, N., De Kler, M. and Vanderzel, J. (2006) The Influence of Different Core Material on the FEA Determined Stress Distribution in Dental Crowns. Dental Materials, 22, 234-242. http://dx.doi.org/10.1016/j.dental.2005.04.034

[8] Boschian Pest, L., Cavalli, G., Bertani, P. and Gagliani, M. (2003) Adhesive Post-Endodontic Restorations with Fiber Posts: Push-Out Tests and SEM Observations. En: Arte y Ciencia de los Materiales Odontológicos, Ediciones Avances, Madrid, 49-57. 
[9] Eskitascioglu, G., Belli, S. and Kalkan, M. (2002) Evaluation of Two Posts Core Systems Using Two Different Methods (Fracture Strengths Test and a Finite Elemental Analysis). Journal of Endodontics, 28, 629-633. http://dx.doi.org/10.1097/00004770-200209000-00001

[10] Barjau Escribano, A., Sancho-Bue, J.L., Torner Navarro, L., Rodríguez Cervantes, P.J., Pérez González, A. and Sánchez Marín, F.T. (2006) Influence of Prefabricated Post Material on Restored Teeth: Fracture Strength and Stress Distribution. Operative Dentistry, 31, 47-54. http://dx.doi.org/10.2341/04-169

[11] Libman, W.J. and Nicholls, J.I. (1995) Load Fatigue of Teeth Restored with Cast Post and Core and Complete Crowns. The International Journal of Prosthodontics, 8, 155-161.

[12] Langer, B., Stein, S.D. and Wagenberg, B. (1981) An Evaluation of Root Resection. A 10 Year Study. Journal of Periodontology, 52, 719-722. http://dx.doi.org/10.1902/jop.1981.52.12.719

[13] Li, L., et al. (2006) Three Dimensional Finite Element Analysis of Weakened Roots Restored with Different Cements in Combination with Titanium Alloy Posts. Chinese Medical Journal, 119, 305-311.

[14] Manocci, F., Ferrari, M. and Watson, T.F. (2001) Microleakage of Endodontically Treated Teeth Restored with Fiber Posts and Composite Cores Alter Cyclic Loading: A Confocal Microscopic Study. Journal of Prosthetic Dentistry, 85, 284-291. http://dx.doi.org/10.1067/mpr.2001.113706

[15] Holmes, D.C., Diaz Arnold, A.M. and Leary, J.M. (1996) Influence of Post Dimension on Stress Distribution in Dentin. Journal of Prosthetic Dentistry, 75, 140-147. http://dx.doi.org/10.1016/S0022-3913(96)90090-6

[16] Ko, C.C., Chu, C.S., Chung, K.H. and Lee, M.C. (1992) Effects of Posts on Dentin Stress Distribution in Pulpless Teeth. Journal of Prosthetic Dentistry, 68, 421-427. http://dx.doi.org/10.1016/0022-3913(92)90404-X

[17] Eraslan, O., Aykent, F., Yücel, M.T. and Akman, S. (2009) The Finite Element Analysis of the Effect of Ferrule Height Onstress Distribution at Post-and-Core-Restored All-Ceramic Anterior Crowns. Clinical Oral Investigations, 13, 223227. http://dx.doi.org/10.1007/s00784-008-0217-5

[18] Pegoretti, A., Frambri, L., Zappini, G. and Bianchetti, M. (2002) Finite Element Analysis of a Glass Fiber Reinforced Composite Endodontic Post. Biomaterials, 23, 2667-2682. http://dx.doi.org/10.1016/S0142-9612(01)00407-0

[19] Lanza, A., Aversa, R., Rengo, S., Apicella, D. and Apicella, A. (2005) 3D FEA of Cemented Stell Glass and Carbon Posts in a Maxillary Incisor. Dental Materials, 21, 709-715. http://dx.doi.org/10.1016/j.dental.2004.09.010

[20] Adanir, N. and Belli, S. (2008) Evaluation of Different Post Lengths’ Effect on Fracture Resistance of a Glass Fiber Post System. European Journal of Dentistry, 2, 23-28.

[21] Soares, C.J., Soares, P.V., de Freitas Santos-Filho, P.C., Castro, C.G., Magalhaes, D. and Versluis, A. (2008) The Influence of Cavity Design and Glass Fiber Posts on Biomechanical Behavior of Endodontically Treated Premolars. Journal of Endodontics, 34, 1015-1019. http://dx.doi.org/10.1016/j.joen.2008.05.017

[22] Soares, C.J., Santana, F.R., Castro, C.G., Santos-Filho, P.C., Soares, P.V., Qian, F. and Armstrong, S.R. (2008) Finite Element Analysis and Bond Strength of a Glass Post to Intraradicular Dentin: Comparison between Microtensile and Pushout Tests. Dental Materials, 24, 1405-1411. http://dx.doi.org/10.1016/j.dental.2008.03.004

[23] Dietschi, D., Duc, O., Krejci, I. and Sadan, A. (2008) Biomechanical Considerations for the Restoration of Endodontically Treated Teeth: A Systematic Review of the Literature, Part II (Evaluation of Fatigue Behavior, Interfaces, and in Vivo Studies). Quintessence International, 39, 117-129.

[24] Newman, M.P., Yaman, P., Dennison, J., Rafter, M. and Billi, E. (2003) Fracture Resistance of Endodontically Treated Teeth Restored with Composite Posts. Journal of Prosthetic Dentistry, 89, 360-367. http://dx.doi.org/10.1067/mpr.2003.75

[25] Hayashi, M., Takahashi, Y., Imazato, S. and Ebisu, S. (2006) Fracture Resistance of Pulpless Teeth with Posts Cores and Crowns. Dental Materials, 22, 477-485. http://dx.doi.org/10.1016/j.dental.2005.03.017

[26] Maccari, P.C., Conceição, E. and Nunes, M. (2003) Fracture Resistance of Endodontic Treated Teeth Restored with Three Different Prefabricated Esthetic Posts. Journal of Esthetic and Restorative Dentistry, 15, 25-31. http://dx.doi.org/10.1111/j.1708-8240.2003.tb00279.x

[27] Cormier, C.J., Burns, D.R. and Moon, P. (2001) In Vitro Comparison of the Fracture Resistance and Failure Mode of Fiber, Ceramic and Conventional Post Systems at Various Stages of Restoration. Journal of Prosthodontics, 10, 26-36. http://dx.doi.org/10.1111/j.1532-849X.2001.00026.x

[28] Gordon, J.E. (1984) The New Science of Strong Materials or Why You Don’t Fall trough the Floor. University Press, Princeton. 